\title{
Determinants of adverse neonatal outcomes among postnatal women in Dar es Salaam -Tanzania
}

\author{
Abubakari S Gwelo, Jackline V Mbishi
}

Department of Mathematics and Statistics Studies, Mzumbe University.

\begin{abstract}
:
Background: Neanatal comploications are the commonest problems facing babies in Tanzania. An attempt has been made to investigate determinants of neonatal outcomes among postnatal women.

Methods: Using a case-contrrol study design, 165 women were selected from 3 health facilities, where they had had antenatal care (ANC), labour, delivery and post natal care.

Results: Chi- square test revealed that gestational age (p-value, 0.01), HIV status (p-value, 0.000) and malaria ( $\mathrm{p}$-value, $0.001<0.05)$ were significantly associated with adverse neonatal outcomes.

Conclusion: The study concluded that implementation of community-based intervention is needed to ensure survival of newborns.

Keywords: Neonatal outcomes, postnatal women.

DOI: https://dx.doi.org/10.4314/ahs.v19i2.15

Cite as: Gwelo AS, Mbishi JV. Determinants of adverse neonatal outcomes among postnatal women in Dar es Salaam-Tanzania. Afri Health Sci.2019;19(2): 1924-1929. bttps:/ / dx.doi.org/10.4314/abs.v19i2.15
\end{abstract}

\section{Background}

Globally, it is recognized that approximately thirty millions new borns worldwide are characterized with low birth weight and hence becoming one of the leading determinant of mortality and disability ${ }^{1}$. This implies that weight at birth is an important indicator of mortality both at individual and community level. Adverse neonatal outcomes such as death, low birth weight (LBW) and preterm birth are common in developing countries including Tanzania ${ }^{2}$. In most sub-Saharan countries including Tanzania, HIV infection has become a leading medical complication of pregnancy and cause of maternal and neonatal morbidity and mortality ${ }^{3}$. Fortunately, anti-retroviral medication and good obstetric practice have greatly reduced both maternal death and transmission of HIV

\section{Corresponding author:}

Abubakari S Gwelo,

Mzumbe University,

Faculty of Science and technology

P. O. Box 87, Mzumbe,Morogoro +255713032938

Email: abugwelo@gmail.com infection to the infant ${ }^{4}$. It has been reported that low birth weight, prematurity, and infection including HIV, are the main factors that contribute to neonatal mortality ${ }^{5,6,7}$. Low birth weight remains a public health problem in many parts of the world and is associated with a range of health problems, lasting disabilities and even death ${ }^{8}$.

Tanzania is making efforts in reducing child mortality, but has demonstrated slower progress due to high levels of neonatal outcomes 9 . About 51,000 newborns die each year, which places it among the top five countries with the most newborn deaths in sub-Saharan Africa ${ }^{10,11}$.

According to a study by Xiao et $\mathrm{al}^{12}$ in China, it was concluded that no significant relationship exists between maternal HIV infection and adverse pregnancy outcomes. In Canada, Macdonald et $\mathrm{al}^{13}$ concluded that women living with HIV were more likely to undergo caesarean section and deliver preterm. In United State of America, HIV infected women with concomitant STI's were reported to have a higher risk of spontaneous preterm birth. ${ }^{14}$ Mitgitti et $a 1^{15}$ in Thailand reported that low birth weight was associated with positive maternal HIV status.

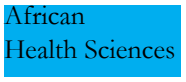

(C) 2019 Gwelo et al. Licensee African Health Sciences. This is an Open Access article distributed under the terms of the Creative commons Attribution License (https://creativecommons.org/licenses/BY/4.0), which permits unrestricted use, distribution, and reproduction in any medium, provided the original work is properly cited. 
The studies conducted in Nigeria ${ }^{16}$ and South Africa ${ }^{17}$ reported that adverse event of low birth weight, preterm delivery retained independent association with HIV infection. ${ }^{18}$ In Tanzania, it is documented that HIV infected women are at a higher risk of adverse pregnancy outcomes $^{19,20,21}$

The existing studies in Tanzania were designed on site specific, targeting specific groups and none has utilized routine Health Management Information System (HMIS) data. Thus this study focused on investigating determinants of neonatal outcomes among postnatal women. The key strength of this paper is on examining the general neonatal outcomes including low birth weight (LBW), infant mortality and preterm, unlike the existing papers that focused on a either LBW alone, infant mortality or preterm.

\section{Materials and methods Research design}

This was an observational study that employed a case control design. Cases were all the adverse neonatal outcomes , while the control group were women without neonatal outcomes. The cases were recruited from health centers; control group was similarly selected from a population of health centers.

\section{Area of study}

The study was conducted at Ilala which is one of the five municipals found in Dar es Salaam region of Tanzania. The study involved three public health facilities namely Hospital, Health Centre and Dispensary.

\section{Target population and Outcome of interest}

Target population was the cohort of all women who received; ANC, labor and delivery and postnatal care in the health facilities between January 2014 to November 2016. The outcome variable was the adverse neonatal outcome defined as a newborn from a selected case or control with any of the following outcome, low birth weight, born prematurity, low Apgar score or death and still birth (fresh and macerated).

\section{Sample and sampling procedure Sample of the study}

A sample is the sub-group of the population which should be representative in the sense that each sampled unit represents the characteristics of the known number of a unit in the population ${ }^{21}$. Sample size was obtained by using the formula developed by Kelsey ${ }^{22}$ given by;

$$
n_{1}=\frac{\left(z_{\propto / 2}+z_{1-\beta}\right)^{2} \bar{p} \bar{q}(r+1)}{r\left(p_{1}+p_{2}\right)^{2}}
$$

Where

$n_{2}=r n_{1}$

$n_{1}=$ Number of cases

$n_{2}=$ Number of controls

Standard normal deviate for two tailed test based on alpha level (related to confidence interval level).

Standard normal deviate for one tailed test based on beta level (related to the power level)

\section{Ratio of controls to cases}

The sample size calculation considered a two-sided confidence level at $95 \%(\alpha=5 \%), Z \alpha / 2=Z 0.25=1.96)$ and a power (\% chance of detecting) of $80 \%(\mathrm{Z} 1-\beta=\mathrm{z} 0.2$ $=0.845)$. The ratio of controls to cases was taken to be 4. Thus the actual sample size was obtained as follows;

$\mathrm{n} 2=\mathrm{rn} 1=4(33)=132$

The minimal sample size needed for the study was estimated to be $33+132=165$

\section{Sampling procedure}

This study used probability sampling procedure particularly simple random sampling techniques to select cases and controls. Using the registers for ANC, delivery and Postnatal, two separate lists of cases and controls was made (for the defined period) to develop sampling frame for each. The list of patients with their profiles was assigned random number and finally the targeted sample size was easy selected using SPSS. Since the study employed the secondary data that had already been recorded, the information of the individuals selected were taken for this analysis. Selection started by cases to obtain the required sample, then controls were selected afterwards. 


\section{Data collection method}

This study employed secondary data available at health facilities which were primarily collected using a questionnaire that contained variables from three registers (i.e. ANC, labor and delivery and postnatal). The information retrieved from the recorded data includes HIV and malaria status, age of mother, gestational age, parity factors, number of pregnancies, history of stillbirth, parity level, anemia and blood pressure status.

\section{Statistical model}

Chi-squared test was used to determine the association between variables, and binary logistic regression model to check the influence of variables to the occurrence of adverse neonatal outcomes. In logistic regression, the probability of $\mathrm{Y}$ occurring given known values of $\mathrm{Xi}$ is predicted as;

Where $i=1,2,3 \ldots \ldots \ldots .165$ and $j=1,2 \ldots 5$

Where $\pi \mathrm{i}$ is the probability of respondent $\mathrm{i}, \mathrm{Xij}$ are different variables associating with adverse neonatal outcomes namely HIV status, clinical factors, parity factors, socio-demographic factors and gestation age,$\beta j$ stands for the parameters and $\beta 0$ is a constant term.

\section{Results}

Association between neonatal outcomes and several fac- tors Chi- squared test was used to test association between each factor and combined indicators of adverse neonatal outcomes. In checking whether demographic factors particularly age of mother are related to the neonatal outcome, the results revealed insignificant relationship ( $p$-value of $0.204>0.05$ ). Contrary to the findings on mother's age, gestational age was significant linked to adverse of neonatal outcomes as evidenced with its corresponding p-value of $0.01<0.05$.Simialry, the HIV status was highly significant associated with the occurrence of neonatal outcomes ( $\mathrm{p}$-value, $0.000<0.05$ ).

Three parity factors namely parity levels, previous number of pregnancy and history of still birth were tested for significance association . Results indicate that parity level ( $\mathrm{p}$-value, $0.941>0.05$ ), previous number of pregnancy ( $\mathrm{p}$-value $0.378>0.05)$ and history of still birth ( $\mathrm{p}$-value, $0.13>0.05)$ are not associated with adverse neonatal outcomes .In the same way, three clinical factors particularly anemia status, blood pressure and malaria infection of a mother were also tested. Findings show that anemia ( $p$-value, $0.535>0.05$ ) and blood pressure ( $\mathrm{p}$-value, $0.316>0.05)$ had no relationship with adverse neonatal outcomes. However, there was a significant association between malaria infection and neonatal outcomes ( $\mathrm{p}$-value, $0.001<0.05)$.

Table 1: Association between neonatal outcomes and various factors

\begin{tabular}{|c|c|c|c|c|c|}
\hline \multirow[t]{2}{*}{ Factors } & \multirow[t]{2}{*}{ Subcategory } & \multicolumn{3}{|c|}{ Neonatal outcomes } & \multirow[t]{2}{*}{$\mathrm{p}$-value } \\
\hline & & No & Yes & Total & \\
\hline \multirow{3}{*}{ Mothers age } & 18 -25years & 27 & 29 & 56 & \multirow{3}{*}{0.204} \\
\hline & 26-34years & 28 & 54 & 82 & \\
\hline & $35+$ years & 9 & 18 & 27 & \\
\hline \multirow{3}{*}{ Gestation age } & 1st-trimester & 6 & 13 & 19 & \multirow{3}{*}{0.01} \\
\hline & 2nd-trimester & 51 & 59 & 110 & \\
\hline & 3rd-trimester & 7 & 29 & 36 & \\
\hline \multirow{4}{*}{ Parity level } & 0_Parity & 15 & 26 & 41 & \multirow{3}{*}{0.941} \\
\hline & 1_Parity & 22 & 33 & 55 & \\
\hline & >1_Parity & 27 & 42 & 69 & \\
\hline & 1st_Pregnancy & 13 & 23 & 36 & \\
\hline \multirow[t]{2}{*}{ Pregnancy } & 2-3_Pregnancies & 39 & 51 & 90 & \multirow[t]{2}{*}{0.378} \\
\hline & $>3$ Pregnancies & 12 & 27 & 39 & \\
\hline \multirow{2}{*}{ History of Stillbirth } & Never & 56 & 79 & 135 & \multirow{2}{*}{0.13} \\
\hline & At least 1 & 8 & 22 & 30 & \\
\hline \multirow{2}{*}{ HIV status } & HIV negative & 55 & 77 & 132 & \multirow{2}{*}{0.000} \\
\hline & HIV positive & 1 & 32 & 33 & \\
\hline \multirow{2}{*}{ Anemia } & Normal & 38 & 55 & 93 & \multirow{2}{*}{0.535} \\
\hline & Anemic & 26 & 46 & 72 & \\
\hline \multirow{2}{*}{ Malaria } & Negative & 61 & 58 & 119 & \multirow{2}{*}{0.001} \\
\hline & Positive & 3 & 43 & 46 & \\
\hline \multirow{2}{*}{ Blood pressure } & Abnormal & 46 & 65 & 111 & \multirow{2}{*}{0.316} \\
\hline & Normal & 18 & 36 & 54 & \\
\hline
\end{tabular}




\section{Discussion}

This study showed that malaria during pregnancy is significantly associated with neonatal outcome ( $p$-value 0.001), and this implies that infected women with malaria during pregnancy had a high possibility of delivering newborn with neonatal outcome. This result was similar to those of previous studies in which malaria in pregnancy was highly related with preventable low birth weight of newborn in women of all pregnancy orders in sub-Saharan Africa ${ }^{22}$. This result implies that despite several efforts made to minimize the burden of malaria in pregnancy, relationship between malaria and neonatal outcome particularly infant mortality is stable. This study revealed association of adverse neonatal outcomes and maternal HIV infection. This is consistent with study in South Africa which found that HIV infected women and adverse outcome were significant ${ }^{23}$. A study conducted in Nigeria ${ }^{24}$ concluded that infected women are prevalent in Nigeria and it is highly associated with infant low birth weight. It is also similar with the past studies conducted in other parts of African continent ${ }^{25,26}$, including studies conducted in Tanzania ${ }^{27}$. While the results indicate a non statistical significance association between neonatal outcomes and parity factors, the situation was quite different to the case of gestational age where by its association with neonatal outcomes was significant. This finding concurs with the past study conducted in Tanzania ${ }^{28}$. Multiple pregnancies were not significantly associated with neonatal outcome unlike the past studies ${ }^{29,30}$ which reported significant relationship.

Despite the fact that anemia during pregnancy is well recognized as among one of the public problem that significantly contributes to the neonatal outcomes, the finding shows no significant association with neonatal outcomes. This finding contrasted with those of other studies ${ }^{31}$. Similarly the past studies revealed a significant association between age of the mother and neonatal outcome $e^{32}$, the current study did not show significant association. The main reason of this contract is due to inadequate sample size which lowers the power of the statistical test. With large sample and even population based studies, the results might be quite different. This limitation of the study that should be considered when we need to generalize the results

\section{Conclusion}

With good antenatal care and multidisciplinary approach, HIV-infected women can ensure quality care of mothers and newborns. In order to increase infant survival, implementation of community-based intervention is also needed and should address basic education, prevention of malaria in pregnancy and poverty eradication. Similarly to optimize the survival of children, the key objective of perinatal research should focus on minimizing the incidence of neonatal outcomes.

\section{Conflict of interest}

None declared.

\section{Reference}

1. World Health Organization. Feto-maternal nutrition and low birth weight. World health Organization, Geneva. Available at: http://www.who. int/nutrition/topics/ feto_maternal/en. Accesed on June 20, 20018(2011)

2. Hornstra G, Uauy R, Yang X. The impact of maternal nutrition on the offspring. Nestle Nutrition Workshop Series Pediatric Program, 2004; Vol.25

3. Onah HE, Obi SN, Agbata TA, Oguanuo TC. Pregnancy outcome in HIV-positive women in Enugu, Nigeria. Journal of Obstetrics and Gynaecology, 2017;27(3), 271274. https://doi.org/10.1080/01443610701195108

4. Fageeh WMK. Presentation and pregnancy outcome of HIV-positive women in Jeddah, Saudi Arabia. International Journal of Gynecology \& Obstetrics, 2011;113(3), 239240. https://doi.org/10.1016/j.ijgo.2010.12.012

5. Kazaura MR, Kidanto HL, Massawe SN. Levels trends and risk for early neonatal mortality at Muhimbili National Hospital Tanzania 1999-2005. East African Journal of Public Health, 2006; 3(2), 10-13.

6. Lawn JE, Cousens S, Zupan J, Team LNSS. 4 million neonatal deaths: when? Where? Why? The Lancet, 2005; 365(9462), 891-900. https://doi.org/10.1016/S01406736(05)71048-5

7. Taha TET, Dallabetta GA, Canner JK, D Chiphangwi J, Liomba G, Hoover DR, Miotti PG. The effect of human immunodeficiency virus infection on birthweight, and infant and child mortality in urban Malawi. International Journal of Epidemiology, 1995; 24(5), 1022-1029. https:/ / doi.org/10.1093/ije/24.5.1022

8. Mosha TCE, Philemon N. Factors influencing pregnancy outcomes in Morogoro Municipality, Tanzania. 
Tanzania Journal of Health Research, 2010; 12(4), 243 251. http://dx.doi.org/10.4314/thrb.v12i4.51795

9. Barros FC, Bhutta ZA, Batra M, Hansen TN, Victora $C G$, Rubens CE. Global report on preterm birth and stillbirth (3 of 7): evidence for effectiveness of interventions. BMC Pregnancy and Childbirth, 2010;10(1), S3. doi: 10.1186/1471-2393-10-S1-S3.

10. Dhingra U, Gittelsohn, J., Moh'd Suleiman, A., Moh'd Suleiman, S., Dutta, A., Ali, S. M., ... Sazawal, S. Delivery, immediate newborn and cord care practices in Pemba Tanzania: a qualitative study of community, hospital staff and community level care providers for knowledge, attitudes, belief systems and practices. Indian Journal of Pregnancy and Childbirth, 2014 14(1), 173. https://doi. org/10.1186/1471-2393-14-173

11. Penfold S, Hill Z, Mrisho M, Manzi F, Tanner M, Mshinda H, Schellenberg JRMA. A large cross-sectional community-based study of newborn care practices in southern Tanzania. PloS One, 2010;5(12), e15593. https:// doi.org/10.1371/journal.pone.0015593

12. Xiao P-L, Zhou Y-B, Chen Y, Yang M-X, Song X-X, Shi Y, Jiang Q-W. Association between maternal HIV infection and low birth weight and prematurity: a meta-analysis of cohort studies. BMC Pregnancy and Childbirth Journal, 2015;15(1), 246. https://doi.org/10.1186/ s12884-015-0684-z

13. Macdonald EM, Ng R, Yudin MH, Bayoumi AM, Loutfy M, Raboud J, Glazier RH. Postpartum Maternal and Neonatal Hospitalizations Among Women with HIV: A Population-Based Study. USA: Mary Ann Liebert., 2015;31(10), 967-972. https://doi.org/10.1089/ aid.2015.0047

14. Burnett E, Loucks TL, Lindsay M. Perinatal outcomes in HIV positive pregnant women with concomitant sexually transmitted infections. Infectious Diseases in Obstetrics and Gynecology, 2015.http://dx.doi. org/10.1155/2015/508482

15. Mitgitti R, Seanchaisuriya P, Schelp FP, Marui E, Yanai H. Low birth weight infants born to HIV-seropositive mothers and HIV-seronegative mothers in Chiang Rai, Thailand. Southeast Asian Journal of Tropical Medicine and Public Health, 2008;39(2), 273.

16. Ezechi OC, Oladele DA, Kalejaiye OO, Oke BO, Ohwodo HO, Adu RA, David AN. (2013). Pregnancy, obstetric and neonatal outcomes in HIV positive Nigerian women. African Journal of Reproductive Health, 2013;17(3), 160-168.

17. Kennedy D, Fawcus S, Kroon M. The effect of mater- nal HIV status on perinatal outcome at Mowbray Maternity Hospital and referring midwife obstetric units, Cape Town: original article. South African Journal of Obstetrics and Gynaecology, 2012; 18(1), 7-10.

18. Coley JL, Msamanga GI, Fawzi MCS, Kaaya S, Hertzmark E, Kapiga S, Fawzi WW. The association between maternal HIV. Infection and pregnancy outcomes in Dar es Salaam, Tanzania. BJOG: An International Journal of Obstetrics \& Gynaecology, 2001; 108(11), 1125-1133.https:// doi.org/10.1111/j.1471-0528.2003.00269.x

19. Dreyfuss ML, Msamanga GI, Spiegelman D, Hunter DJ, Urassa EJN, Hertzmark E, Fawzi WW. Determinants of low birth weight among HIV-infected pregnant women in Tanzania. The American Journal of Clinical Nutrition, 2001; 74(6), 814-826. https://doi.org/10.1093/ ajcn/74.6.814

20. Zack RM, Golan J, Aboud S, Msamanga G, Spiegelman D, Fawzi W. Risk factors for preterm birth among $\mathrm{HIV}$-infected tanzanian women: a prospective study. $\mathrm{Ob}$ stetrics and Gynecology International Journal, 2014; Article ID 261689, http://dx.doi.org/10.1155/2014/261689

21. Latham B. Sampling: What is it. Quantitative Research Methods-, 2007; Texas Tech University

22. Guyatt HL, Snow R. W. Impact of malaria during pregnancy on low birth weight in sub-Saharan Africa. Clinical Mmicrobiology Reviews, 2004;17(4), 760-769. http// doi.org/CMR.17.4.760-769.2004

23. Rollins NC, Coovadia HM, Bland RM, Coutsoudis A, Bennish ML, Patel D, Newell ML. (2007). Pregnancy outcomes in HIV-infected and uninfected women in rural and urban South Africa. JAIDS Journal of Acquired Immune Deficiency Syndromes, 2007: 44(3), 321-328. http// doi.org10.1097/QAI.0b013e31802ea4b0

24. Aribodor DN, Nwaorgu OC, Eneanya CI, Okoli I, Pukkila-Worley R, Etaga HO. Association of low birth weight and placental malarial infection in Nigeria. The Journal of Infection in Developing Countries, 2009,3(08), 620623. https://doi.org/10.3855/jidc.554

25. Nkhoma ET, Kalilani-Phiri L, Mwapasa V, Rogerson SJ, Meshnick SR. Effect of HIV infection and Plasmodium falciparum parasitemia on pregnancy outcomes in Malawi. The American Journal of Tropical Mmedicine and Hygiene, 201287(1), 29-34.

26. Ayisi JG, Van Eijk AM, Ter Kuile FO, Kolczak M S, Otieno JA, Misore AO, Nahlen BL. The effect of dual infection with HIV and malaria on pregnancy outcome in western Kenya. Aids, 2003; 17(4), 585-594, https://doi. org/10.4269/ajtmh.2012.11-0380 
27. Siza JE. Risk factors associated with low birth weight of neonates among pregnant women attending a referral hospital in northern Tanzania. Tanzania Journal of Health Research, 2008; 10(1):1-8, http://dx.doi.org/10.4314/ thrb.v10i1.14334

28. Mosha TCE, Philemon N. Factors influencing pregnancy outcomes in Morogoro Municipality, Tanzania. Tanzania Journal of Health Research, 2010;12(4), 243-251, http://dx.doi.org/10.4314/thrb.v12i4.51795

29. Ugwu R, Eneh A. The Proportion Of Low Birth Weight Babies Due To Small For Gestational Age (SGA) And Prematurity In Port Harcourt, South-South Nigeria-Changing Trends. The Internet Journal of Pediatrics and Neonatology, 2010, 13(1). http//.doi.org/10.13189/ ujph.2015.030206

30. Adamson H. Low birth weight in relation to maternal age and multiple pregnancies at Muhimbili National Hospital. Dar-es Salaam Medical Students' Journal, $2007(2)$, 55-58.

31. Kheir AE, Ali RB, Musa EA. Maternal anemia and neonatal outcome in a tertiary care hospital in Sudan. Journal of Disease and Global Health, 2016; 7(4), 169-173. 32. De Vienne CM, Creveuil C, Dreyfus M. Does maternal age increase the risk of adverse obstetric, fetal and neonatal outcomes: a cohort study. European Journal of $\mathrm{Ob}$ stetrics \& Gynecology and Reproductive Biology, 2009; 147(2), 151-156, https://doi.org/10.1016/j.ejogrb.2009.08.006 